\title{
PASOLINI E CALVINO: A LITERATURA DOS AUTORES
}

\author{
Maria Betânia Amoroso* \\ Universidade Estadual de Campinas
}

Resumo: No texto procura-se comentar a natureza do conceito de literatura em autores modernos italianos, a partir de reflexões sobre a obra de Pier Paolo Pasolini e Italo Calvino. São também sondadas as inter-relações nessas obras entre gêneros 'menores', autobiografia, fragmento e literatura e história. Contrariamente a uma perspectiva crítica que defende a ideia de que o século XX teria tido uma literatura pura em contraposição a uma literatura impura, evidenciam-se os outros caminhos e as outras propostas para o que é considerado como literário na obra desses dois grandes autores do período. Através de operações que privilegiaram o fragmento, o inacabado, as anotações e a releitura, ambos redimensionam o que é menor no campo literário. Através de operações editoriais que definiram e deram forma à própria obra, ambos afirmaram projetos em que o autobiográfico - coral e transbordante, no caso de Pasolini, transparente ou, por vezes, densamente metafórico, no caso de Calvino ocupa espaço relevante.

Palavras-chaves: Italo Calvino. Pasolini. Literatura e fragmento. Literatura e autobiografia. Literatura e história.

Lendo um dos livros do escritor espanhol Enrique Vila-Matas, me deparo com a seguinte reflexão sobre a literatura italiana:

(...) o diário de Pavese pertencia a um período da cultura mundial no qual se costumava integrar a experiência existencial com a ética da história. Um período ao qual o suicídio de Pavese parece marcar um limite cronológico. E também me disse que se o diário de Pavese estava tragicamente ancorado na vida, o de Gide e o de Gombrowicz - mais próximos da minha sensibilidade - o estavam na literatura, que é um mundo autônomo, uma realidade própria, não tem nenhum contato com a realidade porque é uma realidade em si mesma, uma opinião pessoal minha com a qual seguramente Pavese não estaria de acordo (VILA-MATAS, 2005, p. 181).

Nessas observações, escritas por um autor para o qual as fronteiras entre a reflexão crítica e a produção ficcional são partes integrantes, ou melhor, constituintes, de seus 'romances', encontro algumas das mais interessantes questões dos estudos literários como a

Esta obra está licenciada sob uma Licença Creative Commons.

\footnotetext{
* É professora e pesquisadora da Universidade Estadual de Campinas (Departamento de Teoria Literária), Livre Docente na área de Literatura Comparada. E-mail: betamor@uol.com.br
}

Anu. Lit., Florianópolis, v. 20, n. Esp 1, p. 24-31, 2015. ISSNe 2175-7917 
dos gêneros considerados menores, a definição de literatura, as relações entre realidade e ficção, o autobiografismo/biografismo e a figuração do autor nas obras. São esses os temas que me tocam mais de perto - de modo especial, se sondados na tradição literária moderna italiana - e estão por detrás da ideia de apresentar em um encontro sobre Italo Calvino observações que partam de Pasolini.

A aproximação entre Pasolini e Calvino, como sabemos, tem história. Ao centro talvez esteja o livro de Carla Benedetti, Pasolini contra Calvino. Por uma literatura impura, publicado em 1998.

Em 21 de janeiro do mesmo ano, o crítico e historiador da literatura italiana, Asor Rosa, escreveu no jornal La Repubblica uma longa resenha. O título era $O$ triângulo dos narcisos. Sintetizando, ele dizia: "Eu realmente penso que os nomes de Calvino, Pasolini e Fortini constituem o verdadeiro, o grande 'triângulo das forças', sobre o qual se encerra uma fase histórica da literatura italiana (...)" (ROSA, 1998).

Um pouco antes, no dia 15 de janeiro, o escritor Antonio Tabucchi também escrevera, sobre o livro, no Corriere della sera, outra resenha: "As mudanças de estação da literatura. Queneau e Calvino, dois grandes jogadores do século que termina” (TABUCCHI, 1998, p. 19).

Relidos dezesseis anos depois, a ideia mais forte que perpassa o que os três críticos escreveram é a do final do século sugerindo necessariamente o fim de alguma coisa em literatura e, ainda, há a convicção de que o século XX teria tido algo facilmente identificável como literatura (pura ou impura). Embora sejam perspectivas críticas ainda ativas, no meu caso, a operação editorial que levou à publicação de nove volumes contendo, numa variedade incrível de gêneros, a obra de Pasolini convulsiona e sugere outros caminhos e outras ideias para se pensar a literatura desse autor - mas não só a dele - e a sua própria concepção de literatura - mas não só a sua - ou, dito de outra forma, faz crer que passamos muito tempo imaginando que não somente nós, estudiosos e críticos, mas os autores também sabiam o que era literatura e que literatura intencionavam fazer.

A grande característica dessa operação editorial capitaneada substancialmente pelo escritor e crítico Walter Siti está em ter dado destaque ao processo de "acumulação e deslocamento", característico de Pasolini, de pensar os textos para publicação, o que, comenta o crítico, implicou em dois movimentos muito diversos entre si: o do escrever e o do publicar sem contudo pensá-los como mais ou menos 'puros'. Seriam, segundo o crítico, pensados em continuidade e como etapas da conquista do 'não-acabado'. 
Siti encontra essa operação pasoliniana indicada na contracapa do livro Ali dos olhos azuis, contracapa esta escrita quase certamente por Pasolini. Renomeia a operação como a "da farsi" ao "non fatto" - "a se fazer" ao "não acabado". Na contracapa lemos:

Se quisermos identificar nesta longa e atormentada parábola [e escritura e a publicação do material] um ponto de partida e um ponto de chegada, poderíamos dizer que os contos aqui reunidos se lançam como contos "a serem feitos" para chegar, os últimos, a contos "não acabados" [tradução minha] (PASOLINI, 1999, p. 1953).

A "longa e atormentada parábola" indicada pelo autor, resume todas as idas e vindas, os percalços, as dúvidas quanto ao que e como publicar, dos primeiros anos da década de 50 até a publicação do livro Ali dos olhos azuis, em 1965; ao lado disso, o que Siti procura evidenciar com sua edição dos Meridiani é que a fragmentação, o inacabado, a reescritura até o infinito são o projeto de literatura, a ideia de literatura pasolinianos e não um acidente de percurso que se configura no livro póstumo e, justamente, inacabado Petrolio.

A descrição feita pelo crítico e editor daquilo que encontrou nas pastas relativas ao livro, nos fornece uma ideia de movimento intermitente da busca pela literatura da qual é difícil escapar quando se procura entender o que era o literário para Pasolini. Nos primeiros anos da década de 50, o escritor tem a ideia de publicar uma coletânea de páginas romanas; dez anos depois volta ao projeto mas com uma perspectiva totalmente diferente. O que mais impressiona o crítico é a quantidade de 'introduções' escritas: páginas de premissas, prefácios em versos, copiados e recopiados, muitas vezes com diferenças mínimas de uma versão para a outra; posfácios com inúmeras versões, em prosa e verso; índices, indicando os textos a serem incluídos, acompanhados pela data de composição, não como mero registro cronológico mas como referência para o que virá depois e o que veio antes da publicação.

A movimentação criada pelo deslocamento dos textos que saem de um projeto-livro e entram para outro, ou mudam de gênero, as múltiplas instruções para o uso não são, portanto, exclusividade de Petrolio, uma obra inacabada, nem uma eventualidade do momento da publicação de um novo livro, mas constituem o modo de ser de sua literatura; anotações, estudos, fragmentos, trechos abandonados não são a parte impura de uma literatura pura.

Embora as observações tenham sido feitas a partir de Ali dos olhos azuis, seria possível apontar o mesmo movimento em tudo o que Pasolini escreve. O que surpreende, na verdade, é que a crítica, em particular a italiana, sempre indicou Calvino, e não Pasolini, como um escritor que abusava das instruções para uso na sua literatura ou apontava para Calvino, e não Pasolini, quanto ao caráter de escritor-editor das próprias obras. Há quanto 
tempo comentam-se os prefácios e as reorganizações dos livros de Calvino, as notas editoriais, por ser ele quase um protótipo nas letras italianas do escritor pós-moderno. É de sua autoria o prefácio que começa inúmeras vezes, e a cada recomeço oferece um novo movimento que é de releitura do livro prefaciado, mas em Petrolio encontram-se movimentos muito semelhantes de autoria de Pasolini (PASOLINI, 1998) ${ }^{1}$. Parece-me evidente que o fato de haver tantas instruções não autoriza que se determine serem esses materiais menores porque prefácios, notas ou obra inacabada. É justamente através deles que os autores falam de suas literaturas. Não seriam as trilogias outro sinal dessa busca sem fim? As séries, sequências, as trilogias, também não eram exclusividade de Calvino, já que o que viria a ser Ali dos olhos azuis foi pensado por Pasolini como o terceiro volume da trilogia cujos dois outros volumes seriam Ragazzi di vita e Una vita violenta. Nesse quadro, tanto a correspondência como o diário ganham nova importância porque provavelmente serão esses o lugar da reflexão do escritor sobre sua literatura. Nesse lugar se delineia o projeto, e o movimento autor/ obra pode ser flagrado, introduzindo assim o inacabado no sentido que se quiser dar ao termo.

O que estou querendo ressaltar é que esses escritores modernos da literatura italiana indicavam para quem quisesse acompanhá-los o pouco interesse em manter categorias tão caras ao século XX - obra finalizada/ obra acabada/ obra pura em oposição à obra incompleta/ inacabada/ impura; do mesmo modo, sobrepuseram as vestes de editor às de escritor, tornando-as uma única segunda pele, e incorporaram os materiais 'menores' das notas, das cartas, nos textos críticos escritos para jornais à "obra". Caberia aqui perguntar por que os textos 'impuros' de Calvino, aqueles escritos para jornais, por exemplo, não foram ainda publicados. E talvez valesse a pena dar mais atenção àquele comentário que nos conta ter sido hábito de Calvino distribuir os textos que estava trabalhando em mesas diferentes e, caminhando entre as mesas, ia escrevendo seus livros concomitantemente. Há uma dinâmica significativa implicada nisso: tudo o que escrevia, incluindo o gesto da escritura, fazia parte da sua busca pela literatura.

Há um segundo tópico e, para introduzi-lo, retorno a Asor Rosa destacando a palavra "narciso" que compunha o título de seu artigo: narciso, narcisismo querendo significar, até onde posso compreender, a importância que essas figuras acabaram por ter no século XX na

\footnotetext{
${ }^{1}$ Livro composto por anotações ao invés de capítulos, dedica muitas páginas ao que viria antes do 'romance': a primeira anotação é intitulada 'Antefatos' e é constituída por uma única frase, em nota de rodapé: "Este romance não começa"; a série nomeada com o numeral 3, seguidos de letras - de A a E, levam o título de "Prefácio retardado"; na seguinte se lê "O que é um romance? Continua a loucura prefaciatória". V. Petrolio in Pasolini, Pier Paolo. Romanzi e racconti op. cit, p. 1167-1191. [Trad. da A.]
} 
vida ou no campo literário italiano, a consciência que tinham dessa importância e o uso que fizeram desse, que não deixa de ser, poder. Ao mesmo tempo que lia isso, o espectro da "morte do autor", que rondava a crítica por esses mesmos anos, me assombrou com a pergunta: até que ponto o autobiografismo foi removido dessa visão histórico-literária? Até que ponto é peça importante nessa constelação de nomes e temas do século XX (deixo Fortini para outra ocasião) da literatura italiana? E se esse movimento todo fosse o movimento dos 'eus' do autor que se formam, deformam e se reformam?

De início, diria que tanto para um como para outro a figura do autor nunca esteve ausente: se em Pasolini a constatação beira o óbvio, o que pensava Calvino a respeito do argumento pode ser deduzido do seu romance Se um viajante numa noite de inverno no qual todas as figuras da narratologia são ironizadas sem perdão: do autor ao professor de literatura universitário. É um livro onde a figura do autor Calvino é transbordante.

Siti insiste muito, nos inúmeros textos que escreveu, sobre o autobiografismo em Pasolini. Desde os primeiros versos publicados em friulano, por toda a poesia passando pelos ensaios, romances, tudo é autobiográfico (e em seguida faz algumas considerações de ordem psicanalíticas pouco interessantes). Ocorre, porém, que à medida que se lê a obra em conjunto é inevitável a necessidade de precisar o sentido desse autobiografismo. O eu presente está sempre em estado de urgência e a matéria com a qual se exercita não é de modo algum somente autobiográfica, pessoal, individual. É transbordantemente autobiográfico: estão implicados e misturados o sujeito histórico, em carne e osso, que vivia os movimentos da sociedade italiana, e o sujeito lírico que dava voz aos textos, independentemente do gênero. $O$ sentido do "autobiográfico" quando se fala de Pasolini deveria então ser alargado: é um eu coral. É autobiografia e mais alguma coisa. De modo semelhante a Dante, que no seu Inferno escolhe como protagonista do poema o poeta Dante que refaz a crônica da sua vida de homem público em Florença.

A obra completa de Pasolini - nove volumes que abrigam poesia, romance, narrativa, ensaio, jornalismo, crítica literária e de sociedade, teatro, cinema - mostrou como pouco importava para ele a divisão em gêneros, fazendo sobressair essa grande construção de um eu coral que se alimenta daquilo que faz de um poeta um homem público. O que esses milhares de páginas nos revelam com nitidez é que havia uma crença ou confiança em Pasolini de que sua experiência individual coincidia com a experiência histórica do país - é o que nos diz Vila-Matas citado no início deste texto - o que fazia dele um intelectual. Coral significa justamente isso. Nesse mesmo sentido, Alberto Moravia, ao se despedir publicamente do 
amigo, na praça romana Campo dei Fiori, lembrou que com seu assassinato tinha se perdido um poeta civil e que poetas civis não eram fáceis de ser encontrados. Reforça a mesma ideia o texto-manifesto de Pasolini intitulado "Romance dos massacres": o gênero condiz muito com a coralidade e esse texto é uma espécie de seu manifesto. Depois de enumerar crimes e atentados que vinham sendo cometidos e seus responsáveis, iniciando as frases por uma marcante "eu sei", acrescenta:

[...] Eu sei todos esses nomes e sei todos os fatos (atentados às instituições e massacres) dos quais se tornaram culpados.

Eu sei. Mas, não tenho as provas. Não tenho nem mesmo indícios.

$\mathrm{Eu}$ sei porque sou um intelectual, um escritor que busca acompanhar tudo o que acontece, conhecer tudo o que se escreve sobre isso, imaginar tudo aquilo que não se sabe ou que se cala; que coordena fatos também distantes, que reúne as partes desorganizadas e fragmentárias de um quadro político inteiro e coerente, que restabelece a lógica lá onde parece reinar a arbitrariedade, a loucura e o mistério.

Tudo isso faz parte do meu trabalho e do instinto da minha profissão. Acredito que seja difícil que o meu "projeto de romance" esteja equivocado, isto é, que não tenha nexo com a realidade e que as suas referências a fatos e pessoas reais sejam inexatas. Acredito, além disso, que muitos outros intelectuais e romancistas sabem o que eu sei enquanto intelectual e romancista. Porque a reconstrução da verdade sobre o que aconteceu na Itália depois de 1968 não é algo difícil (...) (PASOLINI, 1999, p. 362$367)^{2}$

E Calvino? Que resposta teríamos se alargarmos o conceito de autobiográfico de modo a enxergar na sua obra inúmeras construções de eus autorais? Claudio Milanini na introdução ao segundo volume que recolhe a narrativa do autor dos anos de 1963 a 1983, chama a atenção para o trabalho contínuo de reelaboração dos mesmos temas e para o autobiografismo. Diz ele:

Por um lado, recorre a formas do conto transparentemente autobiográficas, próximas da narração-confissão (...), por outra, constrói textos acentuadamente estratificados, escondendo-se por trás de uma tela de inúmeros narradores fictícios e densas metáforas, quase tornando irreconhecíveis os rastros do próprio "eu", como se aspirasse a alguma espécie de impessoalidade, de anonimato (MILANINI, 1998, p. XIII).

Ainda segundo o mesmo crítico, Giornata d'uno scrutatore e Palomar são livros que se oferecem à sondagem do autobiografismo em Calvino: “... Amerigo Ormea e o senhor Palomar são também, e sobretudo, alter ego em cujas mentes surgem perguntas extremadas, radicais e quanto mais pudicamente formuladas mais oprimentes” (MILANINI, 1998, p. XIII).

\footnotetext{
${ }^{2}$ Pier Paolo Pasolini. Publicado originalmente em Il Corriere della sera 14-11-1974 com o título Che cos'è questo golpe?; hoje em Pasolini. Saggi sulla Politica e sulla Società, Milano: Mondadori, 1999, p. 362-367. Tradução: Danielle Chagas de Lima.
}

Anu. Lit., Florianópolis, v. 20, n. Esp 1, p. 24-31, 2015. ISSNe 2175-7917 
Retomando, para finalizar, Vila-Matas, sua aguda percepção de escritor-crítico sintetiza aquilo que se poderia considerar o que orienta esses escritores: a integração da "experiência existencial com a ética da história", o que torna a intensa reflexão sobre a forma literária indissociável da autobiografia entendida como vida social e política que configura a persona do escritor, o eu autoral. Estamos bem distantes de se considerar suas obras como parte daquilo que se denominou como ficção metaliterária, aquele "mundo a parte" apontado por Vila-Matas como mais congenial. O movimento primeiro, o sentido da busca por suas literaturas, se dão a ver na criação de vozes narrativas que encarnam (e organizam) - cada uma a seu modo - as vicissitudes existenciais de seus autores e suas reflexões sobre a História. Autobiografia, diários e correspondência não podem, assim, ser tidos como menores, muito ao contrário, deveriam ser investigados mesmo quando suas presenças parecem diminutas ou inexistentes.

\section{Referências}

BENEDETTI, Carla. Pasolini contro Calvino. Per una letteratura impura. Torino: Bollati Boringhiere, 1998.

CALVINO, Italo. Romanzi e racconti (1962-1975). v. II. Milano: Mondadori, 1998.

MILANINI, Claudio. Introduzione. In: CALVINO, Italo. Romanzi e racconti (1962-1975). v. II. Milano: Mondadori, 1998, p. 1953.

PASOLINI, Pier Paolo. Saggi sulla Politica e sulla Società. Milano: Mondadori, 1999, p. 362-367. Tradução: Danielle Chagas de Lima.

ROSA, Asor. Il triangolo dei narcisi. La Repubblica. 21 de janeiro de 1998. Disponível em: http://ricerca.repubblica.it/repubblica/archivio/repubblica/1998/01/21/il-triangolo-deinarcisi.html.

TABUCCHI, Antonio. I cambi di stagione della letteratura. Corriere della sera, 15 jan.1998. p. $19 . \quad$ Disponível em: http://archiviostorico.corriere.it/1998/gennaio/15/cambi stagione della letteratura co $0 \quad 980$ 1153693.shtml. Acesso em: 10 jul. 2014.

VILA-MATAS, Enrique. O mal de Montano. Trad. de Celso Mauro Paciornick. São Paulo: Cosac Naify, 2005.

\section{Pasolini and Calvino: The Authors' literature}

Abstract: In the text the purpose is to comment the nature of the concept of literature in modern Italian authors, based on reflections on the work of Pier Paolo Pasolini and Italo Calvino. The inter-relations within such pieces are also approached between 'minor' genres, autobiography, fragment and literature, and history. Contrary to a critical perspective endorsing the notion that the XX century would be marked by a pure literature in opposition 
to an impure literature, findings put other paths and proposals in the spotlight when it goes to what is considered literary in the works of these major authors of the period. Through operations that privilege the fragment, the unfinished, the annotations and the rereading, both have provided new dimensions regarding what is deemed minor in the literary realm. Editorial processes which have defined and shaped the itself were useful for both to affirm projects wherein the autobiographic - coral and overflowing, in Pasolini's case, transparent or at times densely metaphoric, in Calvino's case - occupies a rather relevant position.

Keywords: Italo Calvino. Pasolini. Literature and fragment. Literature and autobiography. Literature and history. 